\title{
Hepatoprotective potentials of water extract of Bauhinia purpurea bark against alcohol induced toxicity
}

\author{
P Chaturvedi ${ }^{\star}$, M Pipedi-Tshekiso, B Moseki and T E Kwape \\ Department of Biological Sciences, University of Botswana, Gaborone, Botswana,.
}

Accepted 22 August, 2011

\begin{abstract}
Bark of Bauhinia purpurea tree was collected and both the water and methanol extracts were prepared. Both extracts were tested for free radical scavenging activities and phenol content. Water extract was then tested for its protective potentials against alcohol induced toxicity. For this experiment, twenty rats were randomly divided into four groups, alcohol control group, normal control and two experimental groups. The rats in alcohol control group received alcohol $(5 \mathrm{~g} / \mathrm{kg})$, rats in normal control were given water. Rats in two experimental groups were administered two doses of methanol extract (50 and $100 \mathrm{mg} / \mathrm{kg}$ respectively) plus alcohol $(5 \mathrm{~g} / \mathrm{kg}$ ) for 30 days. At the end of the experiment, rats were killed after ether anesthesia. Liver and blood samples were collected for biochemical measurements. Parameters measured were thiobarbituric acid reactive substances, serum glutamate oxaloacetate transaminase, serum glutamate pyruvate transaminase, reduced glutathione, glutathione peroxidase, superoxide dismutase, catalase and ascorbic acid. Results showed that both methanol and water extracts scavenged free radicals equivalent to gallic acid scavenging and were found rich in total phenol content. Results of in vivo experiments showed that the water extract inhibited lipid peroxidation, protected the experimental animals from hepatic toxicity and maintained the levels of antioxidants in dose dependent manner.
\end{abstract}

Key words: Lipid peroxidation, anti-oxidants, glutathione, ascorbic acid.

\section{INTRODUCTION}

Alcohol abuse is one of the major problems in African continent and is responsible for significant percentage of hospital admission. Ethanol molecule is small and soluble in both water and lipids, It permeates all tissues of the body and affects most vital functions of virtually all organs including liver, kidney, brain, heart and pancreas (Lieber, 1997). Metabolism of alcohol leads to the generation of free radicals and chain reaction of lipid peroxidation that causes damage of liver and other vital organs. Therefore inhibition of free radicals generation is important in providing protection against hepatic damage. For a long period of time, plants have been a valuable source of natural product for maintaining human health and nowadays, many therapeutic studies are devoted to

\footnotetext{
${ }^{*}$ Corresponding author. E-mail: chaturve@mopipi.ub.bw.
}

plants. Since plants are natural source of antioxidants and hence reduces oxidative stress. Therefore they can be used in the treatment of many oxidative stress originated diseases like hepatic damage.

Bauhinia purpurea, commonly known as Kachnar in Ayurvedic system of medicines, is used as liver tonic and also for the treatment of thyroid disorders. Modern reports also support the thyrogenic effects of the plant (Panda and Kar, 1999). There are different species of Bauhinia and almost all of them have been reported for their biological activities, example, Bauhinia cheilandra and Bauhinia forficata for hypoglycemic effects (Almeida et al., 2006; da Silva et al., 2000), Bauhinia microstachya for antioxidant and free radical scavenging properties (Evandro et al., 2007), Bauhinia variegate for hepatoprotective effects (Bodakhe et al., 2007), and B. purpurea for its antinoceceptive and anti inflammatory properties (Zakaria et al., 2007). 
B. purpurea is world wide in distribution although it is a native plant of Southeastern Asia ranging from India to China. It is a fast growing small to medium size tree. The leaves are smooth and elliptical in shape. Flowers are purple in color and borne on unbranched auxiliary or terminal corymbs in winter and autumn.

Stem bark of $B$. variegate has been reported for antioxidant and hypolipaemic (Rajani and Purnima, 2009) and hepatoprotective effects against $\mathrm{CCl} 4$ induced liver toxicity (Bodakhe et al., 2007). Since, B. purpurea, also belongs to same genus and has been reported for antioxidant and hepatoprotective effects, it has been proposed that this species might have hepatoprotective potentials like $B$. variegate. Therefore, the present study aims to investigate the hepatoprotective potentials of WBP (water extract of $B$. Purpurea) against alcohol induced toxicity. Since water extract is usually used by people for herbal treatment, we have tried to evaluate the protective effects using the same.

\section{MATERIALS AND METHODS}

\section{Collection of plant material and preparation of extracts}

The plant was identified by Dr. M. P. Setshogo of Department of Biological Sciences Herbarium, University of Botswana. The voucher specimen was deposited there. Bark of the tree was collected from the University Campus, washed, chopped into small pieces and sun dried. It was then crushed to powder. Water extract (WBP) was prepared by boiling $200 \mathrm{~g}$ of the powder with water (8 times the volume of powder). The extract (WBP) was filtered and water was evaporated in a rotary evaporizer (BUCHI Rotavapor R$200)$ to get the solid mass. The yield was $29.83 \% \mathrm{w} / \mathrm{w}$. To prepare the methanol extract, the powder was soaked with $70 \%$ methanol for cold extraction for seven days and made methanol free after evaporation under reduced pressure. The yield was 35\%.

\section{Experimental animals}

Male albino SD rats of approximately $200 \mathrm{~g}$ weight were used for all experiments. Initial weights of all the rats were recorded. They were housed in colony cages at an ambient temperature of $25 \pm 2{ }^{\circ} \mathrm{C}$ with $12 / 12 \mathrm{~h}$ cycle of light/darkness. Animals had free access to water ad libitum and were fed on commercial diet bought from Nola Food Corporation, South Africa. Experiment was conducted as per internationally accepted principles for laboratory animal care Unit, Department of Biological Sciences, University of Botswana.

\section{Acute toxicity study}

Animals were orally administered different doses of WBP between 50 to $500 \mathrm{mg} / \mathrm{kg}^{-1}$ and were observed for $24 \mathrm{~h}$ for behavioral change like general activity, sedation, convulsion and mortality. Two doses $50 \mathrm{mg}$ and $100 \mathrm{mg} / \mathrm{kg}$ body weight were selected for the study.

\section{Experimental design}

Twenty rats were used for this experiment and were divided into four groups of five each. Group NC was normal control group administered distilled water, Group AC was alcohol control group received alcohol (5 g/kg) every day, Group E1 was experimental group, received the plant extract $(50 \mathrm{mg} / \mathrm{kg})$ body weight, Group E2 was another experimental group received the plant extract (100 $\mathrm{mg} / \mathrm{kg}$ ). The experiment was run for 30 days. All the administration was oral and done with the help of syringe and tube.

At the end of the experiment, rats were killed by decapitation after ether anesthesia. Blood was collected from brachial artery, plasma was separated from it and frozen $\left(-70^{\circ} \mathrm{C}\right)$. Body weights of rats were taken after every weak.

\section{Statistical analysis}

Programme used for data analysis was Sigma Stat (3.1 version). Data was subjected to descriptive statistics after that differences among the groups were analyzed using two way ANOVA followed by Turkey's test for comparisons.

\section{Phytochemical measurements}

Determination of the free radical scavenging activity by TLC and DPPH staining

Method described by Yeboa and Majinda (2009) has been followed for this estimation. Diluted samples of WBP and MBP were carefully loaded onto aluminium back TLC sheet $(10 \times 10 \mathrm{~cm})$ and kept for drying for two hours. Drops of WBP and MBP extracts $(0.1$ to $10 \mu \mathrm{l})$ dissolved in water $(100 \mu \mathrm{g} / \mathrm{ml})$ were loaded using a microlitre syringe along the row. Gallic acid was used as positive control. After drying, the sheet bearing the dry spots, it was sprayed with $0.2 \%$ DPPH solution. Stained silica layer reveals a light purple back ground with white spots where the radical scavenging activity is present. The intensity of the white color corresponds with the amount of scavenger present.

\section{Determination of total phenol content}

Total phenol content of water extract and methanol extract were determined by the method of Yeboa and Majinda (2009) using Folin- Ciocalteau reagent. $500 \mathrm{mg}$ of the extract is mixed with $5 \mathrm{ml}$ of the solvent (methanol extract was mixed with methanol and water extract was mixed with water). $0.5 \mathrm{ml}$ of Folin-Ciocalteau reagent was added to this mixture. After $3 \mathrm{~min}, 1 \mathrm{ml}$ of saturated sodium carbonate was added to this reaction mixture and was shaked vigorously for $2 \mathrm{~min}$. The mixture was allowed to stand at room temperature for $2 \mathrm{~h}$. The contents were then centrifuged at $2000 \mathrm{~g}$ for $5 \mathrm{~min}$. Absorbance of the supernatant was recorded at $725 \mathrm{~nm}$. A standard curve was prepared using different concentrations of gallic acid. Total phenolic content was expressed as gallic acid equivalents (GAE) from the standard curve using the equation derived by linear regression and expressed as $\mathrm{mg}$ GAE / $\mathrm{g}$ of extract.

\section{Biochemical measurements}

Measurement of the thiobarbituric acid reactive substances (TBARS)

TBARS in plasma was measured by the method described by Tripathi et al.(2001).Lipid peroxidation is measured by the formation of thiobarbituric acid reactive substances (TBARS) such as malondialdehyde (MDA). MDA formed from breakdown of fatty acids, serves as a convenient index for determining the extent of peroxidation reaction. MDA has been identified as the product of lipid peroxidation that reacts with thiobarbituric acid to give red 
species absorbing at $535 \mathrm{~nm} .0 .1 \mathrm{ml}$ of plasma was treated with 2 $\mathrm{ml}$ of TCA-TBA- $\mathrm{HCl}(1: 1: 1)$ mixture and incubated in boiling water bath for ten minutes, then the mixture was cooled and $2 \mathrm{ml}$ of freshly prepared $1 \mathrm{~N} \mathrm{NaOH}$ was added, the absorbance was measured at $535 \mathrm{~nm}$.

\section{Measurement of the reduced glutathione}

Reduced glutathione was measured by the method of Ellman (1959). $0.25 \mathrm{ml}$ of plasma was mixed with $0.5 \mathrm{ml}$ of precipitating buffer (5\%TCA in $1 \mathrm{mM}$ EDTA), It was centrifuged and the supernatant was collected and was mixed with $2.5 \mathrm{ml}$ of $0.1 \mathrm{M}$ phosphate buffer ( $\mathrm{pH}$ 8.0).Colour was developed by adding $100 \mu \mathrm{l}$ DTNB $(0.01 \%)$ and the absorbance was taken at $412 \mathrm{~nm}$.

\section{Superoxide dimutase}

Superoxide dismutase was assayed by the method of Tripathi et al. (2002). The role of superoxide dismutase (SOD) is to accelerate the dismutation of the superoxide radical $\left(\mathrm{O}_{2}{ }^{-}\right)$produced during oxidative energy processes to hydrogen peroxide and molecular oxygen. The assay of SOD activity is based on the principle of inhibitory effects of SOD on reduction of nitroblue tetrazolium dye by superoxide radicals. A single unit of enzyme was expressed as $50 \%$ inhibition of NBT (Nitroblue tetrazolium) reduction $/ \mathrm{min} / \mathrm{mg}$ protein. The reaction mixture contained $150 \mu \mathrm{l}$ EDTA, $600 \mu \mathrm{l}$ methionine, $300 \mu \mathrm{l} \mathrm{NBT}$ and the volume was made up to $2.8 \mathrm{ml}$ by the addition of SOD buffer. $200 \mu \mathrm{l}$ of the plasma was added to the reaction mixture, except in the control. Finally $200 \mu \mathrm{l}$ of riboflavin was added to start the reaction. The test tube was kept under a fluorescent lamp and the reaction kinetics measured for four minutes. The absorbance was read at $560 \mathrm{~nm}$ for four minutes.

\section{Catalase}

Catalase was estimated by the method of Bisswagner (2004). 0.2 $\mathrm{ml}$ of plasma was added to $0.98 \mathrm{ml}$ of $\mathrm{H}_{2} \mathrm{O}_{2}$ - solution $(10 \mathrm{mM})$. The absorption was read at $240 \mathrm{~nm}$ and the catalase activity was calculated using the extinction coefficient of $\mathrm{H}_{2} \mathrm{O}_{2}-(0.071)$ and the activity was expressed as micromoles of $\mathrm{H}_{2} \mathrm{O}_{2}$ oxidized per minute per milligram protein.

\section{Vitamin C}

The method of Roe (1961) was followed for the estimation of ascorbic acid in plasma. Ascorbic acid in the presence of sulphuric acid forms hydrazone with 2, 4 dinitrophenyl hydrazine (DNPH) which gives absorption maxima at $520 \mathrm{~nm}$. The intensity of the colour formed is directly proportional to the concentration of ascorbic acid present in the sample. To $0.4 \mathrm{ml}$ of plasma, $1.6 \mathrm{ml}$ of $10 \%$ TCA was added. The contents were mixed well and allowed to stand for $5 \mathrm{~min}$. They were centrifuged at $2000 \mathrm{rpm}$ for $10 \mathrm{~min}$. Blank and standard were also simultaneously processed with distilled water in the blank tube and the respective standard in the standard tube. $0.4 \mathrm{ml}$ of DNPH reagent was added to $1.0 \mathrm{ml}$ of the supernatant. The stopped tubes were incubated at $37^{\circ} \mathrm{C}$ for three hours. After incubation period the tubes were kept in ice-bath and then $1.6 \mathrm{ml}$ of cold $65 \% \mathrm{H}_{2} \mathrm{SO}_{4}$ was added. The contents were mixed and the colour formed was read at $520 \mathrm{~nm}$ after $30 \mathrm{~min}$.

\section{Measurements of serum glutamate oxaloacetate transaminase (SGOT), serum glutamate pyruvate transaminase (SGPT) and total proteins}

These parameters were diagnosed by commercial kit bought from
Agape Diagnostic, India and manufacturer's guidelines were followed.

\section{RESULTS}

\section{WBP and MBP free radical scavenging activity and total phenol content}

Results of free radical scavenging activity of WBP and MBP are presented in Figures 1 and 2. Strong intensity of white spot appeared quickly at the dose of $10 \mu$ followed by 6 and $5 \mu \mathrm{l}$ in both the cases. The results were similar to the scavenging activity of gallic acid that was used as positive control. Total phenol contents of methanol extract and water extract were equivalent to $183.1 \pm 4.1$ and $151.6 \pm 2.7 \mathrm{mg}$ of gallic acid $/ \mathrm{g}$ of the dried extract respectively.

\section{Acute toxicity}

No mortality and gross change in the behaviour was observed for doses up to $500 \mathrm{mg} / \mathrm{kg}$ body weight.

\section{Effects on marker parameters}

The activities of SGOT and SGPT were significantly enhanced in $A C(p<0.05)$ as compared to $N C$ indicating damage to the liver cell in this group (Table 1). The activities of these enzymes were significantly lowered in EX1 and EX2 $(p<0.05)$ as compared to Group AC. The levels of both enzymes in EX2 differed significantly $(p<0.05)$ from the levels in NC and this indicates towards the normalization of the liver structure in this group. Levels of TBARS in EX1 and EX2 differed significantly $(p<0.05)$ from both $A C$ and NC groups while the levels of total proteins differed significantly from AC (Table 1).

\section{Effects on plasma anti-oxidants}

Effects of WBP administration on plasma antioxidants against alcohol induced toxicity are presented in Table 2. The results showed that alcohol administration for 30 days had significantly reduced the plasma glutathione levels in $A C$ as compared to $N C$ and EX2. In EX1, the levels differed significantly from NC $(p<0.05)$ but the difference was non significant with AC. The levels in EX2 differed significantly $(p<0.05)$ from both $A C$ and NC.

Similarly glutathione reductase activities were also increased in both experimental group as compared to AC $(p<0.05)$. Activities of plasma catalase were significantly increased in EX1 and EX2 as compared to AC but it had not reached the normal activities as in NC $(p<0.05)$.

Activities of plasma SOD showed slightly different pattern. The differences in the levels of SOD were not 


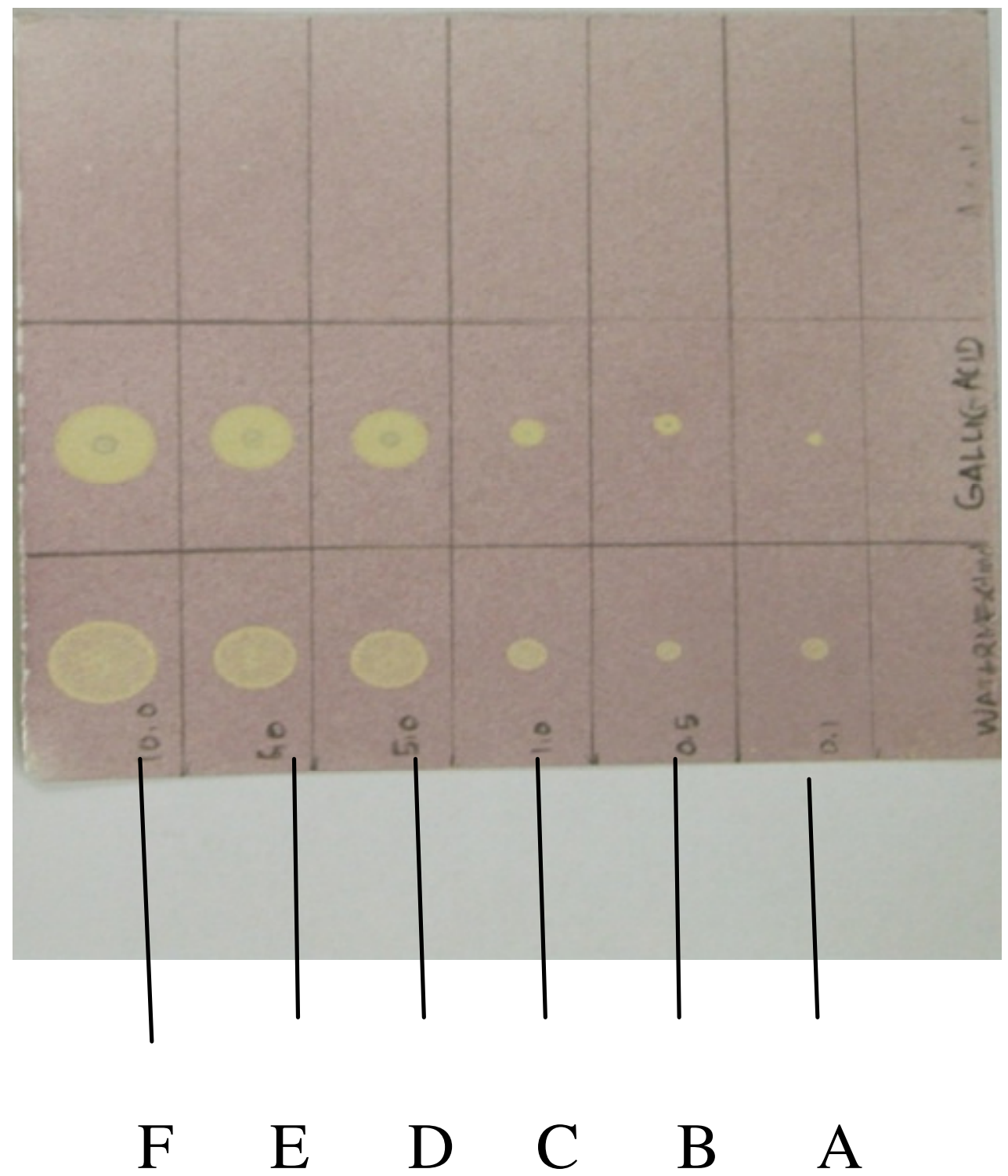

Figure 1. Semi- quantitative TLC -DPPH assay indicating the extent of yellow spot formation of Bauhinia purpurea water extract at different amounts (A) $0.1 \mu \mathrm{l},(\mathrm{B}) 0.5 \mu \mathrm{l},(\mathrm{C}) 1.0 \mu \mathrm{l},(\mathrm{D}) 5.0 \mu \mathrm{l}$, (E) $6.0 \mu \mathrm{l},(\mathrm{F}) 10.0 \mu \mathrm{l}$ with gallic acid used as standard and the solvent (water) used as blank.

significant in EX1 as compared to $\mathrm{AC}$ but the activities in EX2 differed significantly $(p<0.05)$ from both NC and AC.

\section{DISCUSSION}

In the liver, the ethanol is oxidized to cytotoxic acetaldehyde by alcohol dehydrogenase and then to acetate by aldehyde dehydrogenase or xanthine oxidase (Lieber, 1997). This metabolism is accompanied by generation of free radical like ethyl and hydroxyl ethyl radicals. Ethanol inducible cytochrome CYP2E1 has high rate of NADPH oxidase activity that leads to the production of both super oxide anion and hydrogen peroxide at very high rate (Lieber, 1994). Thus, alcohol induced hepatotoxicity is linked to oxidative stress. Acetaldehyde also reacts with macromolecules of hepatic cells and causes liver damage (Zima et al., 2001).

Thiobarbituric acid reactive substances (TBARS) are one of the diagnostic indices of lipid peroxidation due to oxidative stress. A significant increase in the levels of plasma TBARS in alcohol treated groups (AC) clearly indicates the adverse effect of alcohol metabolism (Table 2). Administration of alcohol together with the WBP extract has significantly reduced the deleterious effects of free radicals generated by alcohol metabolism as indicated by the significantly low levels of these substances in EX1 and EX2. Although the level of 


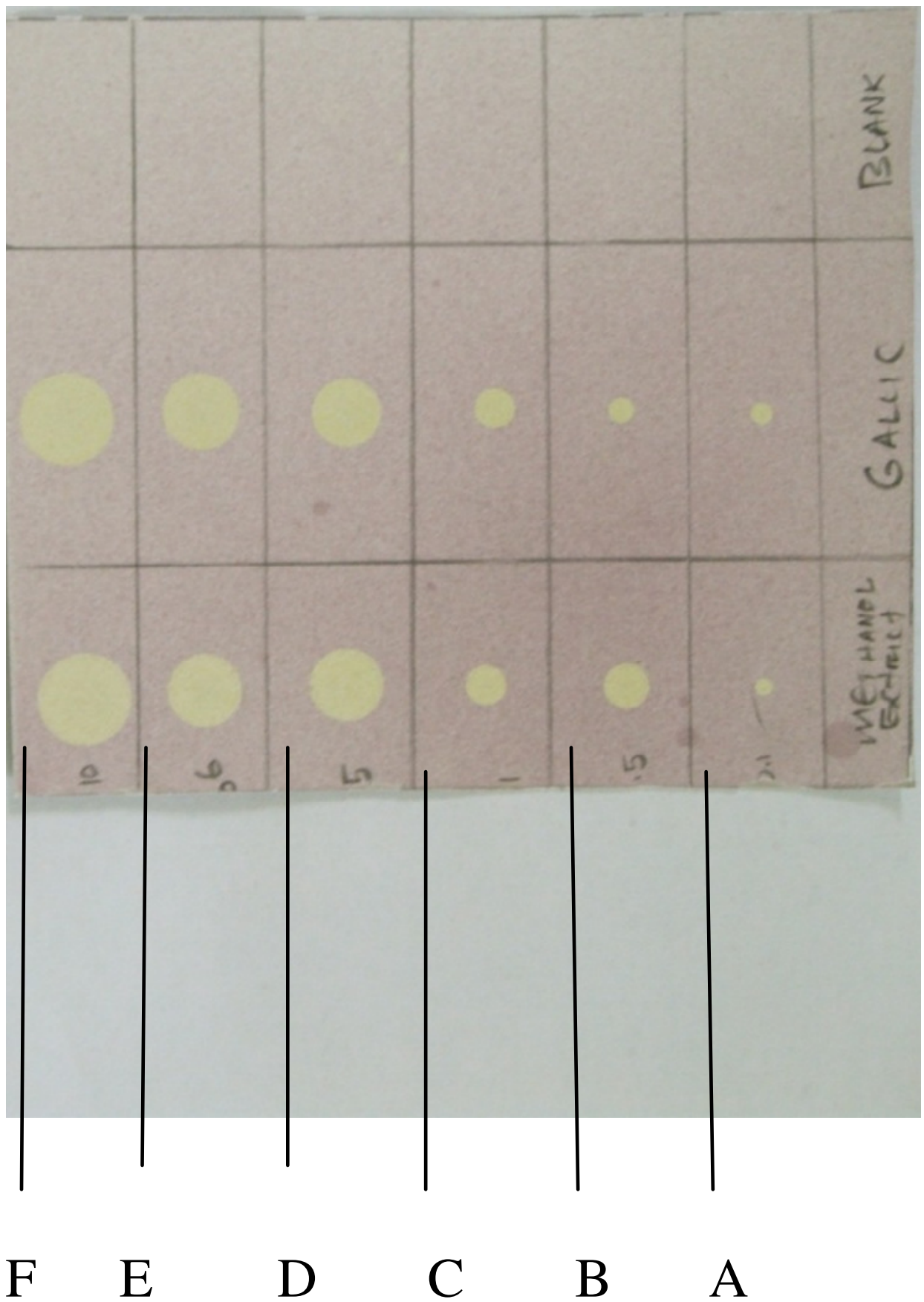

Figure 2. Semi- quantitative TLC -DPPH assay indicating the extent of yellow spot formation of Bauhinia purpurea methanol extract at different amounts(A) $0.1 \mu \mathrm{l},(\mathrm{B}) 0.5 \mu \mathrm{l},(\mathrm{C}) 1.0 \mu \mathrm{l},(\mathrm{D}) 5.0$ $\mu \mathrm{l}$, (E) $6.0 \mu \mathrm{l}$, (F) $10.0 \mu \mathrm{l}$ with Gallic acid used as standard and the solvent(methanol) used as blank.

TBARS in two experimental groups is lower than AC group, it also differs significantly from NC. This clearly shows that although the rate of lipid peroxidation is reduced but not completely prevented. These findings are further supported by low levels of SGOT and SGPT and high levels of total proteins in experimental groups (Table 2)
Excessive alcohol consumption leads to vitamin deficiency (Gerster, 1995). Thus it appears that low levels of Vitamin C in Group AC is because of continuous alcohol administration that has led to the subsequent reduction in reduced glutathione content of plasma and liver. Levels of Vitamin C and reduced glutathione have 
Table 1. Total phenolic content of the extracts of Bauhinia purpurea.

\begin{tabular}{lc}
\hline Extract & TPC $(\mathbf{m g ~ G A E} / \mathbf{g})$ \\
\hline Water & $151.6 \pm 2.7$ \\
$70 \%$ methanol $/ \mathrm{H}_{2} \mathrm{O}$ & $183.1 \pm 4.1$ \\
\hline
\end{tabular}

Values are the average of three trials \pm standard deviation.

Table 2. Effects of Bauhinia purpurea water extract (WBP) on marker parameters of alcohol induced toxicity in albino rats.

\begin{tabular}{lcccc}
\hline Groups & TBARS $(\mathbf{n m o l} / \mathbf{d l})$ & SGOT $(\mathbf{U} / \mathbf{L})$ & SGPT $(\mathbf{U} / \mathbf{L})$ & Total proteins $(\mathbf{m g} / \mathbf{d l})$ \\
\hline AC & $328.8 \pm 2.61$ & $58.41 \pm 2.39$ & $78.8 \pm 1.28$ & $3.76 \pm 0.12$ \\
NC & $64.29 \pm 3.7$ & $25.69 \pm 0.91$ & $45.3 \pm 1.87$ & $6.85 \pm 0.21$ \\
EX1 & $228.6 \pm 7.64^{\mathrm{ab}}$ & $37.13 \pm 3.63^{\mathrm{ab}}$ & $51.49 \pm 1.89^{\mathrm{a}}$ & $4.98 \pm 0.11^{\mathrm{a}}$ \\
EX2 & $126.8 \pm 5.12^{\mathrm{ab}}$ & $35.37 \pm 2.71^{\mathrm{a}}$ & $42.49 \pm 1.28^{\mathrm{a}}$ & $5.93 \pm 0.17^{\mathrm{a}}$ \\
\hline
\end{tabular}

$\mathrm{AC}=$ Alcohol control group administered alcohol ( $5 \mathrm{~g} / \mathrm{kg}$ body weight ) every day; NC- Normal control group received distilled water every day; EX1 and EX2 are two experimental groups that received $50 \mathrm{mg}$ and $100 \mathrm{mg} / \mathrm{kg}$ body weight respectively for 30 days. Values are expressed as mean \pm SEM, $n=5$ in each group. $a=p<0.05$ when compared with $A C ; b=p<0.05$ when compared with NC.

Table 3. Effects of Bauhinia purpurea water extract (WBP) on plasma anti-oxidants against alcohol induced toxicity in albino rats.

\begin{tabular}{lccccc}
\hline Groups & Plasma GSH(mg/dl) & Plasma VIT C(mg/dl) & Plasma GPX (mg/dl) & Plasma CAT(U/L) & Plasma SOD (U/L) \\
\hline AC & $32.36 \pm 3.61$ & $1.6 \pm 0.09$ & $3.47 \pm 0.61$ & $41.66 \pm 1.63$ & $16.89 \pm 1.52$ \\
NC & $88.66 \pm 4.05$ & $2.88 \pm 0.13$ & $14.23 \pm 1.6$ & $85.13 \pm 3.78$ & $35.17 \pm 1.19$ \\
EX1 & $42.9 \pm 3.26^{\mathrm{b}}$ & $2.19 \pm 0.13^{\mathrm{a}}$ & $11.91 \pm 1.16^{\mathrm{a}}$ & $50.73 \pm 1.05^{\mathrm{ab}}$ & $25.47 \pm 0.96^{\mathrm{b}}$ \\
EX2 & $62.04 \pm 2.63^{\mathrm{ab}}$ & $2.94 \pm 0.16^{\mathrm{a}}$ & $15.88 \pm 1.77^{\mathrm{a}}$ & $66.36 \pm 1.79^{\mathrm{ab}}$ & $28.27 \pm 1.32^{\mathrm{ab}}$ \\
\hline
\end{tabular}

$\mathrm{AC}=$ Alcohol control group administered alcohol $(5 \mathrm{~g} / \mathrm{kg}$ body weight $)$ every day; NC- Normal control group received distilled water every day; EX1 and EX2 are two experimental groups that received $50 \mathrm{mg}$ and $100 \mathrm{mg} / \mathrm{kg}$ body weight respectively for 30 days. Values are expressed as Mean \pm SEM, $n=5$ in each group. $a=p<0.05$ when compared with $A C ; b=p<0.05$ when compared with NC.

significantly elevated in both experimental groups as compared to the AC group (Table 3). Reduced rate of lipid peroxidation could be related to the elevated levels of Vitamin C and reduced glutathione. Vitamin $C$ has been shown to scavenge free radicals very efficiently before they reach the cellular membrane. It also reduces the oxidized glutathione to reduced form and thus makes availability of reduced glutathione to the antioxidant system for further scavenging action (Miglani et al., 2003; Kaminski and Boal, 1992). Reduced glutathione in its turn also regenerates Vitamin $\mathrm{C}$ from dehydro-ascorbic acid (Noctor and Foyer, 1998). In the present study, supplementation of alcohol treatment with WBP inhibited the lipid peroxidation (Table 2), maintains the levels of these two water soluble antioxidants and thus strengthens the first line of antioxidants to fight the generated free radicals as a result of metabolism of alcohol.

The enzymatic and non-enzymatic antioxidant systems are intimately linked to each other in scavenging free radicals from the system. SOD is an intracellular produced enzyme and is present in almost every cell of the body. It eliminates reactive oxygen species by reducing superoxide form to hydrogen peroxide (Culotta, 2000). Catalase is present in all body organs being especially concentrated in the liver and erythrocytes. Glutathione peroxidise is present in most aerobic cells in animal tissues. Both the enzymes are responsible for reducing $\mathrm{H}_{2} \mathrm{O}_{2}$ to $\mathrm{H}_{2} \mathrm{O}$ (Husain and Somani, 1997). The glutathione redox cycle is a central mechanism for reduction of hydro-peroxides to water by oxidizing reduced glutathione to oxidized one which in turn is reduced to reduced glutathione by glutathione reductase. An increase in the production of SOD without a subsequent elevation of catalase or glutathione peroxidase leads to the accumulation of hydrogen peroxide, which leads to the accumulation of hydrogen peroxide and ultimately to the hydroxyl radical. In the present study, activities of catalase and glutathione peroxidise are significantly increased in both the experimental groups (Ex12 and EX2) as compared to Group AC (Table 3). The activities of SOD are enhanced significantly only in Group EX2. In EX1, the activities of SOD do not differ significantly (Table 3) from Group AC. 
This indicates that, WBP maintains an intricate balance between these enzymes to avoid over accumulation of $\mathrm{H}_{2} \mathrm{O}_{2}$ in the system.

The protective effects of WBP could be ascribed to the fact that it is rich in antioxidants, particularly phenols. Results of in vitro experiments have demonstrated the significant anti-oxidative properties of WBP. In dot blot and DPPH staining experiment, antioxidant properties are equivalent to anti oxidant capacity of gallic acid. This result is consistent with previous findings of Rajani and Purnima (2009) for B. variegata.

Thus it appears that protective effects of WBP are dose dependent. The effects are more significant at higher dose $(100 \mathrm{mg} / \mathrm{kg})$ against alcohol induced toxicity. WBP scavenges free radicals and thus boosts the antioxidant capacity of organism.

\section{REFERENCES}

Almeida ER, Guedes MC, Albuquerque JF, Xavier H (2006). Hypoglycemic effect of Bauhinia cheilandra in rats. Fitoterapia, 77: 276-278.

Bodakhe B, Jayakar B, Ram A (2007). Hepatoprotective properties of Bauhinia variegata bark extract. Yakugaku Zasshi. 127: 503-507.

Bisswanger H (2004). Practical Enzymology. Wiley-VCH, Weinheim: Germany.

Culotta VC (2000). Superoxide dismutase, oxidative stress, and cell metabolism. Curr Top Cell Regul., 36: 117-132.

Da Silva KL, Biavatti MW, Leite SN, Yunes RA, Delle M F, Cechinel FV (2000). Phytochemical and pharmacognostic investigation of Bauhinia forficata Link. Z Naturforsch, 55: 478-480.

Ellman GC (1959). Tissue sulfhydryl groups. Arch Biochem Biophys., 82: 70-77.

Evandro G, Silva D, Guilherme AB, Alfeu ZF, Rodrigo L, Luis GR, Celso LB, Francilene A, Ana L A, Valquiria L B, Amélia TH, Flávio HR, Felipe DP, José C F M (2007). Antioxidant activities and free radical scavenging potential of Bauhinia microstachya (RADDI) MACBR. (Caesalpinaceae) extracts linked to their polyphenol content. Biol. Pharm. Bull., 30 (8): 1488-1496.
Gerster H (1995). $\beta$-carotene, vitamin $E$ and vitamin $C$ in different stages of experimental carcinogenesis. Eur J. Clin. Nutr., 49: 155-168.

Husain K, Somani SM (1997). Interaction of exercise and ethanol on hepatic and plasma antioxidant system in rat. Pathophysiology, 4: 6974.

Kaminski M, Boal R (1992). An effect of ascorbic acid on delayed-onset muscle soreness. Pain, 50: 317-321.

Lieber CS (1997). Role of oxidative stress and antioxidant therapy in alcoholic and non-alcoholic liver diseases. Pharmacology, 38: 601628.

Leiber CS (1994). Metabolic consequences of ethanol. Endocrinologist, 4(2): 127-139.

Miglani A, Seth RK, Siwach SB (2003). Effect of vitamin C supplementation on reduced glutathione and malondialdehyde in patients with acute myocardial infarction. Clin. Chim. Acta., 327(1-2): 187-188.

Noctor G, Foyer CH (1998). Ascorbate and glutathione: Keeping Active Oxygen under Control. Ann. Rev. Plant Physiol. Plant Mol. Biol., 49: 249-279.

Panda S, Kar A (1999). Withania somnifera and Bauhinia purpurea in the regulation of circulating thyroid hormone concentrations in female mice . J. Ethanopharmacol., 67(2): 233-239.

Rajani GP, Purnima A (2009). In vitro antioxidant and antihyperlipidemic activities of Bauhinia variegata Linn. Ind. J. Pharmacol., 41(5): 227232.

Roe JH (1961). In Methods of Biochemical analysis, Vol. 1 (Glicks Edition) Interscience Publishers Inc, New York: USA, pp. 115-139.

Tripathi YB, Upadhyay AK, Chaturvedi P (2001). Antioxidant properties of Smilax china. Ind. J. Exp. Biol., 39: 1176-1179.

Zakaria ZA, Abdul Rahman NI, Loo YW, Abdul Yaub AH, Sulaiman.MR, Gopalan HK, Fatimah CA (2007). Antinociceptive, anti-inflammatory and antipyretic properties of the aqueous extract of Bauhinia purpurea leaves in experimental animals. Med. Princ. Prac., 16(6): 443-449.

Zima T, Fialova L, Mestek O, Janebova M, Crkovska J, Malbohan I, Stipek S, Mikulikova L, Popov P (2001). Oxidative stress, metabolism of ethanol and alcohol related disease. J. Biomed. Sci., 8(1): 59-70. 